\title{
A COMPARATIVE STUDY OF PARTICLES CHARACTERISTICS, TEMPERATURE SENSITIVITY AND MORPHOLOGY OF PEG/POLY (NIPAM-CO-AMPS) MICROGELS
}

\author{
Ajoy Kumar Saikia**1, UttamKumar Mandal ${ }^{2}$ \\ ${ }^{1}$ Department of Polymer Technology, Delhi Skill and Entrepreneurship University, GND Rohini Campus, Delhi, India \\ ${ }^{2}$ University School of Chemical Technology, GGS Indraprastha University, Dwarka, Delhi, India \\ *Corresponding author: aksaikia2014@gmail.com
}

\begin{abstract}
The temperature sensitive copolymer of microsize hydrogels consist of $\mathrm{N}$-isopropylacrylamide (NIPAM) and 2acrylamido-2 methylpropanesulphonic acid (AMPS) have been synthesized by soap free emulsion polymerization method in the presence of polyethylene glycol (PEG) as macro initiator and $\mathrm{N}, \mathrm{N}^{\prime}$-methylenebisacrylamide (NMBA) as crosslinker. In this work, Dynamic Light Scattering (DLS), Transmission Electron Microscope (TEM) and Atomic Force Microscope (AFM) technique were used for structural analysis of microgels. It was found that particle size observed by TEM and AFM were spherical with a diameter around $103.0 \mathrm{~nm}$ to $133.1 \mathrm{~nm}$ and $121.1 \mathrm{~nm}$ to $189.0 \mathrm{~nm}$. While DLS measurement shows narrow particle size distribution with hydrodynamic diameter from $343.6 \mathrm{~nm}$ to $528 \mathrm{~nm}$ at a temperature $25^{\circ} \mathrm{C}$ and $132.5 \mathrm{~nm}$ to $414.4 \mathrm{~nm}$ at temperature $50^{\circ} \mathrm{C}$ depending on the AMPS content in Microgels samples. The surface roughnesses of particles were observed to be increasing with increased AMPS content. Moreover, decrease in hydrodynamic diameter from $25^{\circ} \mathrm{C}$ to $50^{\circ} \mathrm{C}$ revealed the temperature sensitivityproperty of microgels.
\end{abstract}

Keywords: Copolymerization; Temperature sensitive; Microgels, Swelling ratio.

\section{INTRODUCTION}

Microgels are the colloidal dispersion of gel particles prepared by cross-linked hydrophilic homopolymers or copolymers with characteristic dimensions of 1 1000nm. [1-4]. These particles encompass a wide varieties of different polymer compounds with unique properties for potential applicationns in different fields like targeted drug delivery, cosmetic formulations, cell/protein conjugation, tissue engineering, bioseparation etc [5-7]. The microgels which respond to external stimuli can be either chemical/physical signals or biological signals are known as environmentally responsive microgels. Chemical signals such as $\mathrm{pH}$, ionic strength, solvent or biological signals like enzymes, biomolecules interfere with the molecular interactions between polymeric chains and solutes. Physical signals such as light, temperature, electric field, magnetic field and mechanical stress modify the energies of chain dynamics and molecular interactions. These environmentally responsive microgels show non-linear response to an external signal and therefore, large varieties of different approaches made to develop smart applications in biology, medicine, and nanotechnologies [8-16].
In the last few decades, temperature responsive microgels/nanogels have become major interest to researchers because of their utility to several biomedical applications including controlled drug delivery systems, biomimetic energy transducing devices and separation techniques [17-19]. Most of the temperature responsive microgels are based on Poly ( $\mathrm{N}$-isopropylacrylamide) or related copolymers [20-21]. Poly (N-isopropylacrylamide) have ability to exhibit physiochemical or mechanical changes in presence of small temperature difference and show a phase transition at certain temperature, which cause sudden change in the solvation state. The temperature at which PNIPAM becomes insoluble upon heating is called lower critical solution temperature (LCST). The phase transition of polymer-solvent mixture is the transition from one phase to another involving mutual rearrangement of polymer molecules and its thermodynamic properties. Thus, it shows a discontinuous volume phase transition temperature at $\sim 34.5^{\circ} \mathrm{C}[22,23]$. When temperature is lower than $34.5^{\circ} \mathrm{C}$, the hydrophobicity of polymer chain decreases and its hydrophilicity increases by expanding diameter and volume of microgels. Thereby, the sensitivity of PNIPAM is related to hydrophobic and 
hydrophilic group attached to the PNIPAM molecular chain. The transition temperature PNIPAM microgels can be modified according to specific needs by reducing cross-linking density or adding ionic monomer [24-26]. The phase transition behavior of microgel particle is the key parameter to design the smart materials for different biomedical applications. To understand the phase behavior of microgels particle, one have to go for structural analysis of microgels particle. There are different techniques to structural analysis of microgels particle such as dynamic light scattering (DLS), Static Light Scattering (SLS), atomic force microscope (AFM), transmission electron microscope TEM), scanning electron microscope (SEM). Dynamic light scattering has become the standard technique for measuring particle size in solution state as it has good accuracy and reproducibility [2, 27, 28]. However, hydrodynamic diameter of microgels particle measured by dynamic light scattering are sensitive to surface tails thus, it found larger than corresponding sizes obtained by static light scattering, X-ray scattering, or neutron scattering [29]. Electron microscopy gives a qualitative indication of monodispersity and measured the particle size in dry condition [30, 31].

The TEM is the powerful tool to analyse the quality, shape, size of microgels particle. on the other hand, AFM technique has been used to study the nano or micro particles characteristics as it offers the capability of $3 \mathrm{D}$ visualization in both qualitative, quantitative information about the sample topology including morphology, surface texture, roughness [32]. Image analysis offers the possibility to measure both the size and the shape of particles using their two-dimensional projections. This approach is often considered as an ideal reference technique to validate other particle size distribution characterization methods.

The aim of this work was to investigate the particles size, size distribution, morphology and sensitivity of microgels by means of different techniques.

\section{EXPERIMENTAL}

\subsection{Material}

The monomer N-isopropylacrylamide (NIPAM), 2acrylamido-2-methylpropane sulphonic acid (AMPS) from Sigma-Aldrich, and PEG-6000 from Merck Specialties Pvt. Ltd, India was used as received. An extra pure N, N-methylenebisacrylamide (NMBA) from SRL (India) was used as a cross linker. Ammonia ceric (IV) nitrate, 99.99\% pure from Sigma-Aldrich was dried in oven at $105^{\circ} \mathrm{C}$ for $1 \mathrm{~h}$ prior to use. Double- distilled water drawn from a Millipore purification system was used as solvent.

\subsection{Preparation of microgels}

The copolymer microgels were synthesized via free radical precipitation polymerization in water according to procedures reported in our previous paper [33]. Polymerization was carried out in a round bottom flask connected to a water condenser. Macro initiator was prepared by mixing $4 \mathrm{ml} \quad 0.1 \mathrm{M}\left(\mathrm{NH}_{4}\right)_{2} \mathrm{Ce}\left(\mathrm{NO}_{3}\right)_{6}$ aqueous solution and $10 \mathrm{ml}$ solution of $10 \% \mathrm{PEG}$. Then the measured amount of $\mathrm{N}$-isopropylacrylamide (NIPAM), Acrylamido-2-methylpropane sulphonic acid (AMPS), MBA as cross-linker were added and made the total volume of the solution to $50 \mathrm{ml}$. Nitrogen purged through the solution for 1 hour to remove oxygen prior to polymerization. The polymerization was carried out at $50^{\circ} \mathrm{C}$ for 4 hours under nitrogen atmosphere. The solution was then cooled to room temperature and centrifuged for half an hour (10.000 rpm, Eppendrof $5810 \mathrm{R})$ at $40^{\circ} \mathrm{C}$ and then redispersed in distilled water. This process was repeated three times and then the samples were dried in a vacuum to a constant weight.

\subsection{Characterization of microgels}

The particle size, shape were determined by transmission electron microscope (TEM), Morgagni268D, FEI Company. TEM images were analysed in Image $1.43 \mathrm{q}(\mathrm{NIH}$, Bethesda, MD, USA). The area and perimeter of each particle was extracted before calculating circularity $\left[4 \pi\left(\frac{\text { Area }}{\text { Premeter }^{2}}\right)\right]$ and diameter $\left(\sqrt[x]{\frac{\text { Area }}{\pi}}\right)$ to estimate particles to be spherical.

The atomic force microscopy measurements were performed using AFM in non-contact mode and ambient conditions. Image resolution was between $256 \times 256$ pixels and $500 \times 500$ pixels, Scan speed was between 1 and $5 \mu \mathrm{m} / \mathrm{s}$, scan size $5 \times 5 \mu \mathrm{m}^{2}$ and $10 \times 10 \mu \mathrm{m}^{2}$. Prior to analysis, all the images were flattened to remove artifacts of the image acquisition process. The raw data obtained from microscope were processed in WSxM 5.0 Develop 6.4, Nanotec Electronica S.L open source software using plane leveling algorithm [34]. The particle heights were calculated by thresholding height in topography images and extracting $\mathrm{z}$ range of each particle. The roughnesses of the surface were determined by measuring the root-mean-square (RMS) roughness parameter, define as the root-mean-square average of the height (z) taken from mean data plane, expressed as: 
RMS $=\sqrt{\frac{\sum_{\mathrm{i}=1}^{\mathrm{N}}\left(\mathrm{z}_{\mathrm{i}}-\mathrm{z}_{\text {ave }}\right)^{2}}{\mathrm{~N}}}$

Where $Z_{i}$ is the height value for a particular point in the image $(\mathrm{nm}), \mathrm{Z}_{\text {ave }}$ is the mean height of all the pixels in the image $(\mathrm{nm})$ and $\mathrm{N}$ is the total number of pixels within the image.

To quantify the relationship between the homogeneity of particle size and shape, TEM diameters and AFM heights of particles were combined and described according to the eccentricity statistic distribution [35]:

$\varepsilon=\sqrt{\frac{a^{x}-b^{x}}{a^{2}}}=\sqrt{1-\left(\frac{b}{a}\right)^{2}} 0<\varepsilon<1$

Where $\mathrm{a}$ and $\mathrm{b}$ are half of the ellipse's major and minor axes (diameter and height), respectively. As the eccentricity value ranges from 0 to 1 , the corresponding particle shape will range from spherical $(\varepsilon=0)$ to ellipsoidal $(\varepsilon=1)$.

The hydrodynamic particle size and size distribution of microgel particles were measured at different temperatures ranging from $25^{\circ} \mathrm{C}$ to $50^{\circ} \mathrm{C}$ at constant copolymer concentration in pure water by dynamic light scattering (DLS), Zeta-sizer Nano-S Malvern Instrument. The measurements were made at the scattering angle $\theta=173^{\circ}$ and wavelength $(\lambda)=633 \mathrm{~nm}$.

The swelling ratio (SR) is widely used to characterize the volume phase transition of microgels and defined as [36]:

$\mathrm{SR}=\frac{\mathrm{V}_{\mathrm{S}}}{\mathrm{V}_{\mathrm{C}}}=\left(\frac{\mathrm{R}_{\mathrm{g}}}{\mathrm{R}_{\mathrm{c}}}\right)^{3}$
$\frac{\mathrm{V}_{\mathrm{S}}}{\mathrm{V}_{\mathrm{C}}}=\frac{1}{\emptyset}$

Where $\mathrm{R}_{\mathrm{s}}$ is the hydrodynamic radius at $25^{\circ} \mathrm{C}$ and $\mathrm{R}_{\mathrm{c}}$ is the hydrodynamic radius at $50^{\circ} \mathrm{C}, \mathrm{V}_{\mathrm{S}}, \mathrm{V}_{\mathrm{C}}$ are the volume of swollen and collapse gels respectively, $\varnothing$ is the volume fraction of polymer.

\section{RESULTS AND DISCUSSION}

\subsection{Comparison between Microgel Particles}

The microgels particles characterized by DLS and its hydrodynamic diameter were determined by StokesEinstein relations. Fig. 1 illustrates the temperature dependent particle size and size distribution of copolymer microgels with different AMPS content in water at $25^{\circ} \mathrm{C}$ and $50^{\circ} \mathrm{C}$. The data show that the hydrodynamic diameters of microgels increases from $343.4 \mathrm{~nm}$ to $538 \mathrm{~nm}$ at $25^{\circ} \mathrm{C}$ and $132.5 \mathrm{~nm}$ to 414.8 $\mathrm{nm}$ at $50^{\circ} \mathrm{C}$ with increasing AMPS concentration in the feed recipe but its diameters reduces with increasing temperature. At $25^{\circ} \mathrm{C}$, the bimodal peak with broad size distribution was observed for the microgels sample with low mole\% of AMPS i.e. MG-100, MG-102 and MG-106. Only monomodal peak with narrow size distribution observed for all microgels at $50^{\circ} \mathrm{C}$, which means that the process of aggregation of microgel particles was already completed. At the temperature of $50^{\circ} \mathrm{C}$, which is well above the LCST of PNIPAM, the PNIPAM chains shrink and all individual particles aggregate because of attractive forces i.e. intra/ intermolecular and hydrophobic interaction, which dominate over interaction between polymers with water molecules. At low temperature, the aggregates will dissociate in individual swollen particles which show the broad size distribution. The intensity of microgel particles is found to be increased with increasing AMPS content, which may be due to high particle density. The polydispersity of microgels is strongly influenced by the temperature, as it decreases with an increase in temperature. The trends of increasing hydrodynamic diameter and increase in polydispersity are consistent with TEM and AFM measurements.
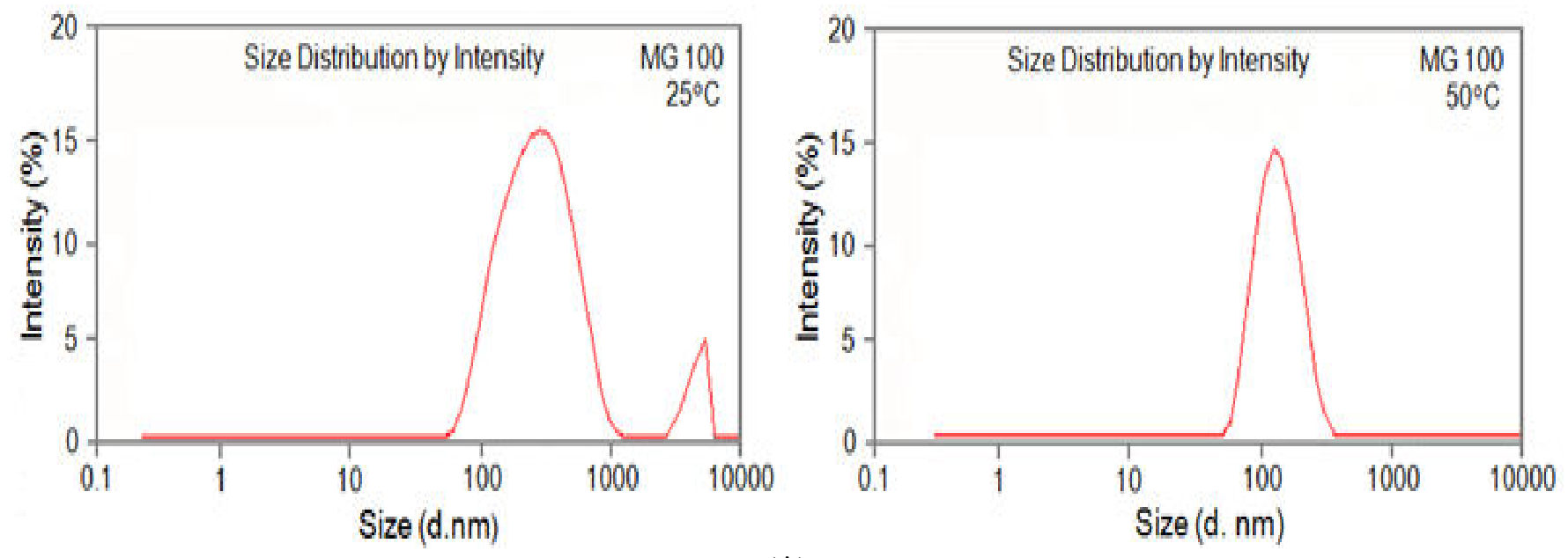

(A) 

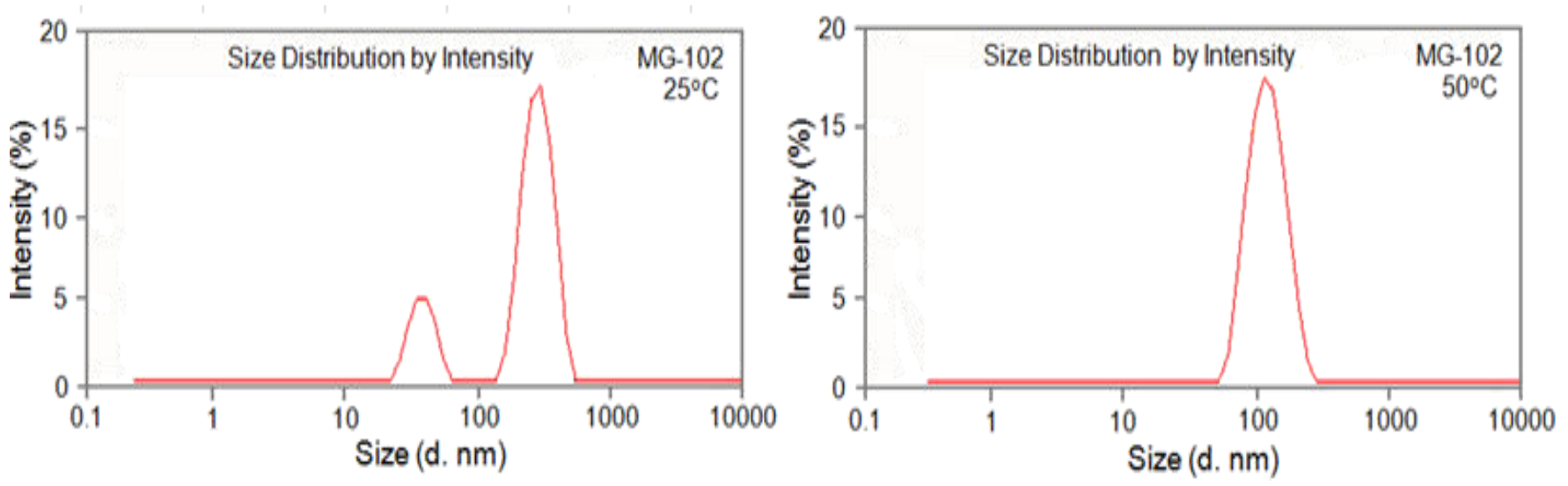

(B)
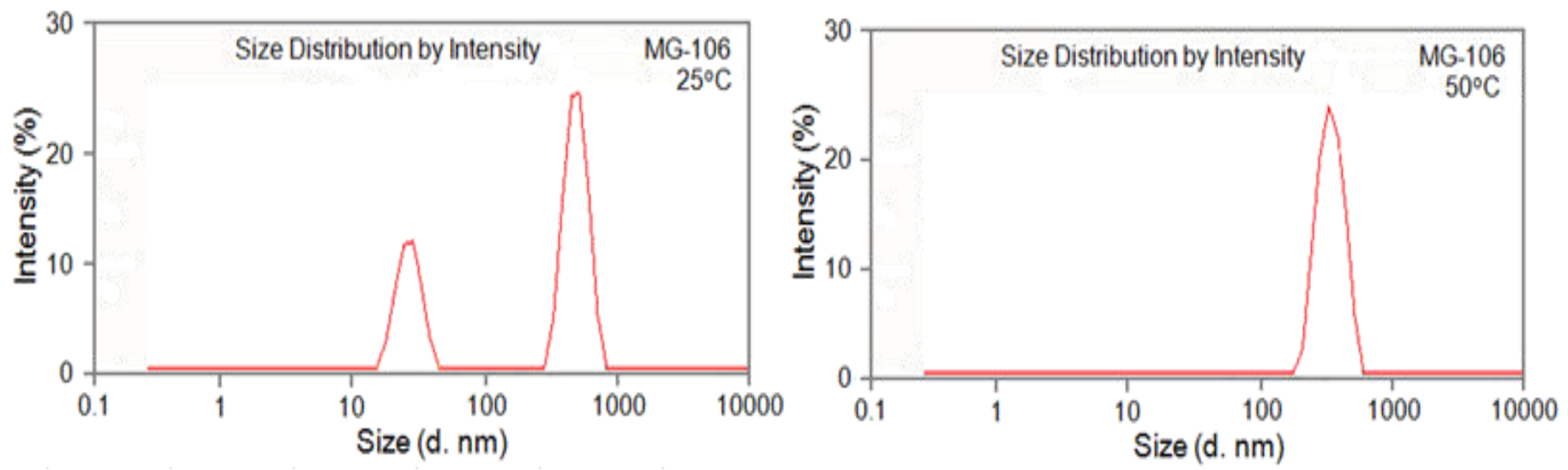

(C)
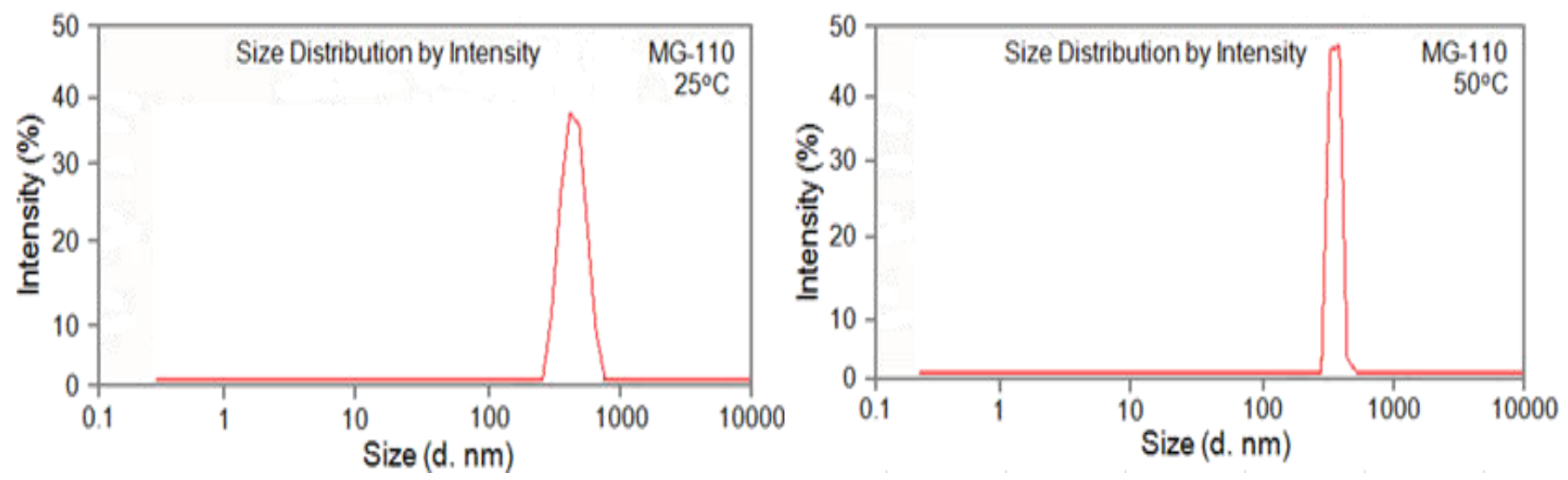

(D)

Fig. 1: The intensity particle size distribution of microgels (A) MG-100 at $25^{\circ} \mathrm{C} \& 50^{\circ} \mathrm{C}$, (B) $\mathrm{MG}-102$ at

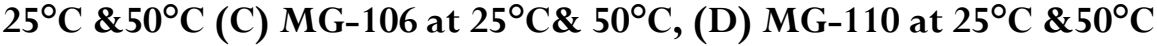

Fig. 2 shows representatives TEM images with their histogram of different microgel particles. Before plotting the histogram, the individual particles were extracted by processing TEM images in Image $1.43 \mathrm{q}$ (NIH, Bethesda, MD, USA) software. The diameter and circularity of different Microgels were calculated from the area and perimeter of each particle by using the formula $\left[4 \pi\left(\frac{\text { Area }}{\text { Premeter }^{2}}\right)\right]$ and diameter $\left(\sqrt[z]{\frac{\text { Area }}{\pi}}\right)$ respectively. The calculated diameter is varying from $\sim 103 \mathrm{~nm}$ to $133 \mathrm{~nm}$ depending on AMPS monomer concentration. The smaller size obtained for the sample MG-100 i.e $103 \mathrm{~nm}$ and its size increasing with increased in amount of functional monomer. The 
particle size distribution also becomes narrow with increasing AMPS content. The possible explanation of increase in the particle size is that, AMPS effect on the chemistry of the particle formation. At polymerization temperature, high concentration of AMPS in the network tends to increase the solubility of copolymer, which means an increased in critical length for phase separation to form precursor particles thus yield larger particles.

The AFM topography images, extracted profile and histogram of different microgels are shown in Fig. 3. The particle size is determined from the Z-hight of the extract profile. The average particle was $121.1 \mathrm{~nm}$ for MG-100, $144.6 \mathrm{~nm}$ for MG-102, 151.3 for MG-106 and $189.0 \mathrm{~nm}$ for MG-110, this value increases with increased AMPS content in microgel samples, the trend is similar to DLS and TEM.

The average diameter obtained by DLS for all microgel samples was higher than those obtained by TEM and AFM as shown in Table 1.

The dynamic light scattering (DLS) is a technique that measures the hydrodynamic diameter of the particle including the solvation layers. As far as DLS is concerned, the theory states that when a dispersed particle moves through a liquid medium, a thin electric dipole layer of the solvent adheres to its surface. This layer influences the movement of the particle in the medium. Thus, the hydrodynamic diameter gives us information of the solvent layer attached to the particle as it moves under the influence of Brownian motion. In our case, microgel particles have long tentacles of PEG chains hanging outside the particle surface and increases the micro viscosity around the particles, thus it gives larger size due to error in actual viscosity in Stokes Einstein Equation. Whereas, TEM and AFM estimating the size in absence of hydration layer. TEM estimate the projected area and perimeter of particles while AFM estimate Z-height of particles from where we can determine the particle diameter. The variation of particle size among TEM and AFM measurement is due to vacuum condition is applied to TEM measurement. Hence, the particle size measured by DLS is always greater than the size estimated by TEM and AFM. The correlations of particle size of micro and nano particles measured through DLS, TEM and AFM are explained by different authors [37].
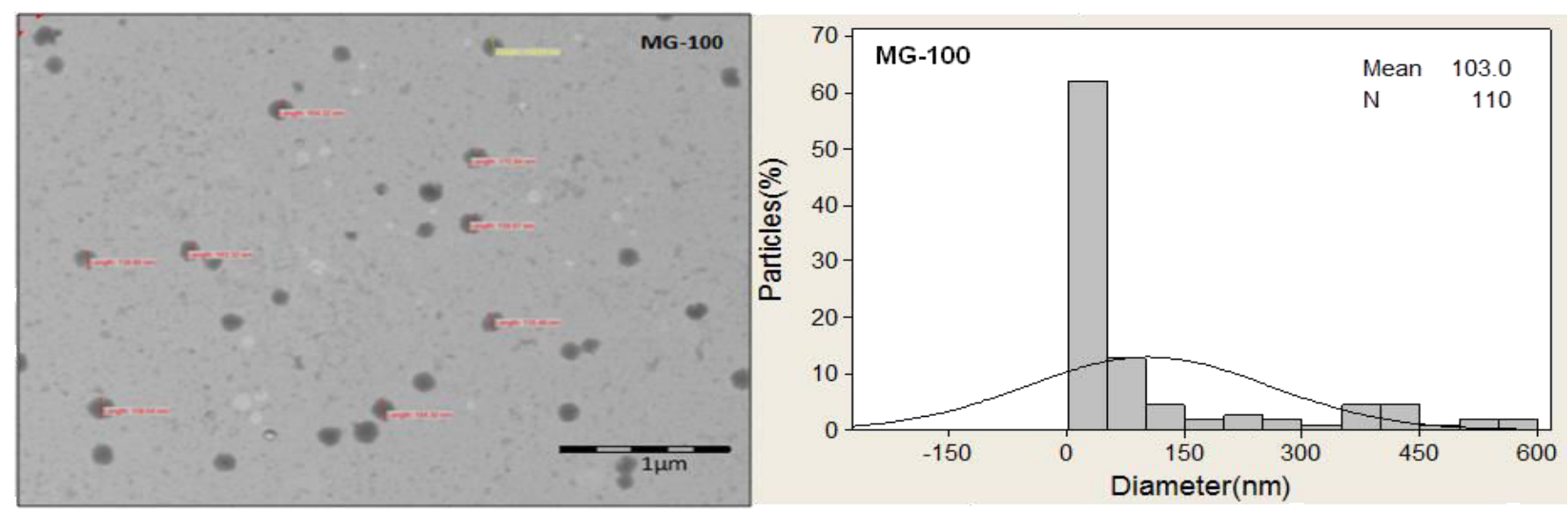

(A)
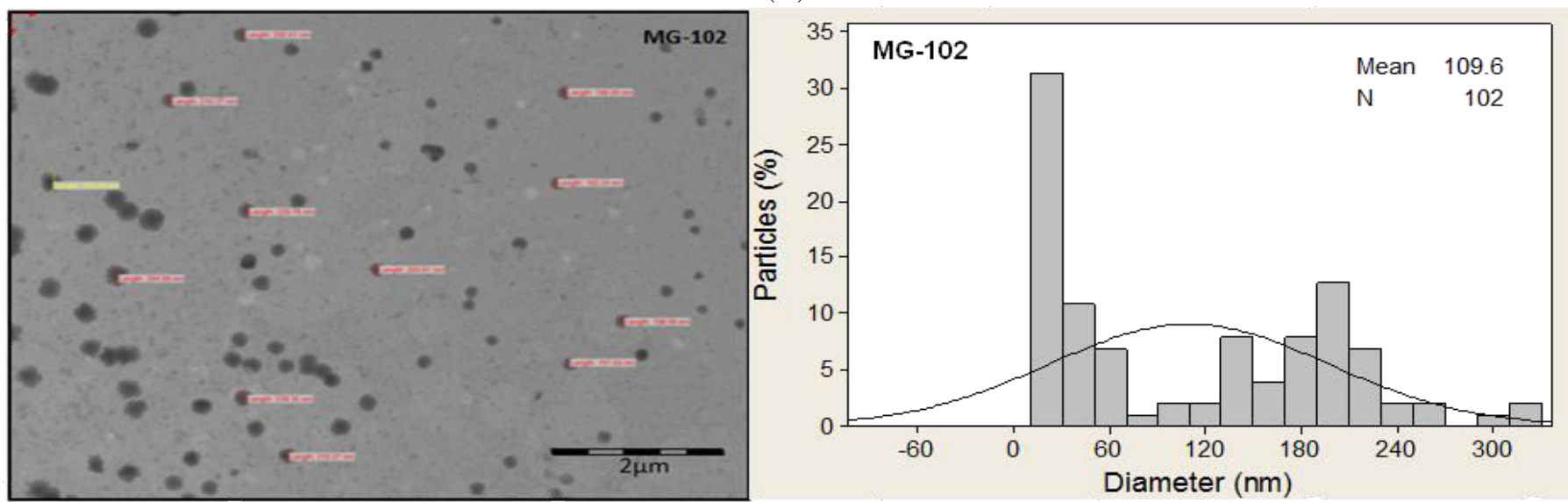

(B) 

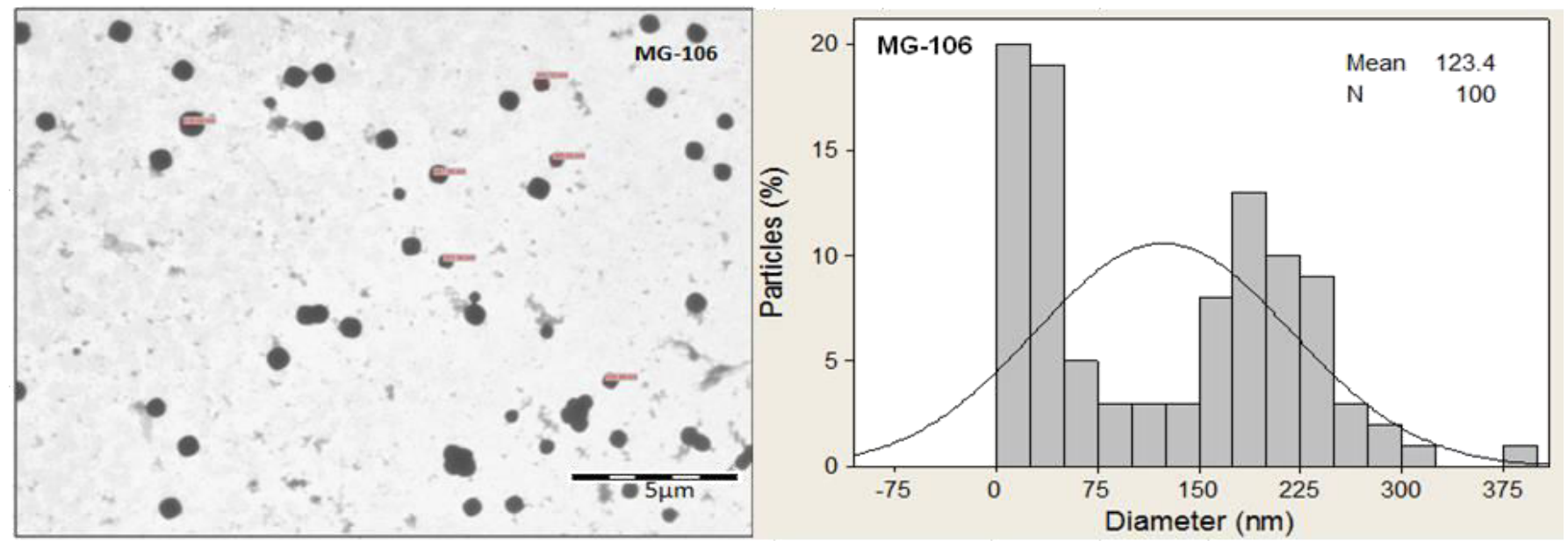

(C)
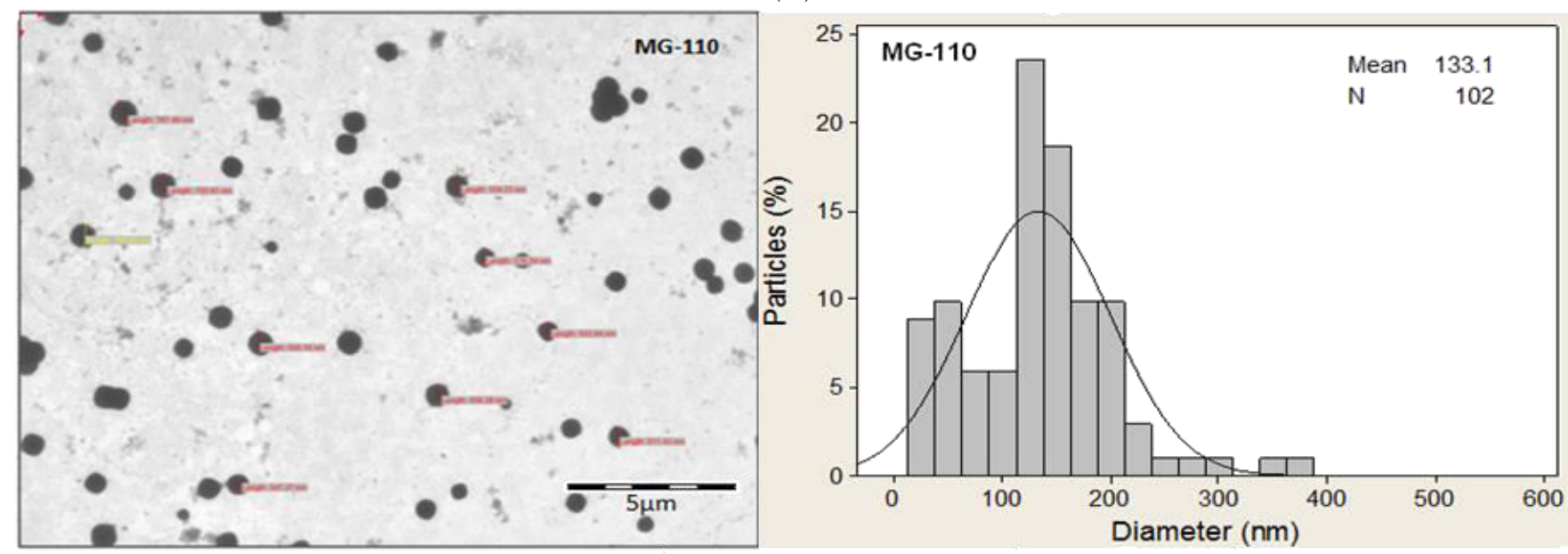

(D)

Fig. 2: The TEM images and their histogram of different microgels (A) MG-100, (B) MG-102 (C) MG-106, (D) MG-110.
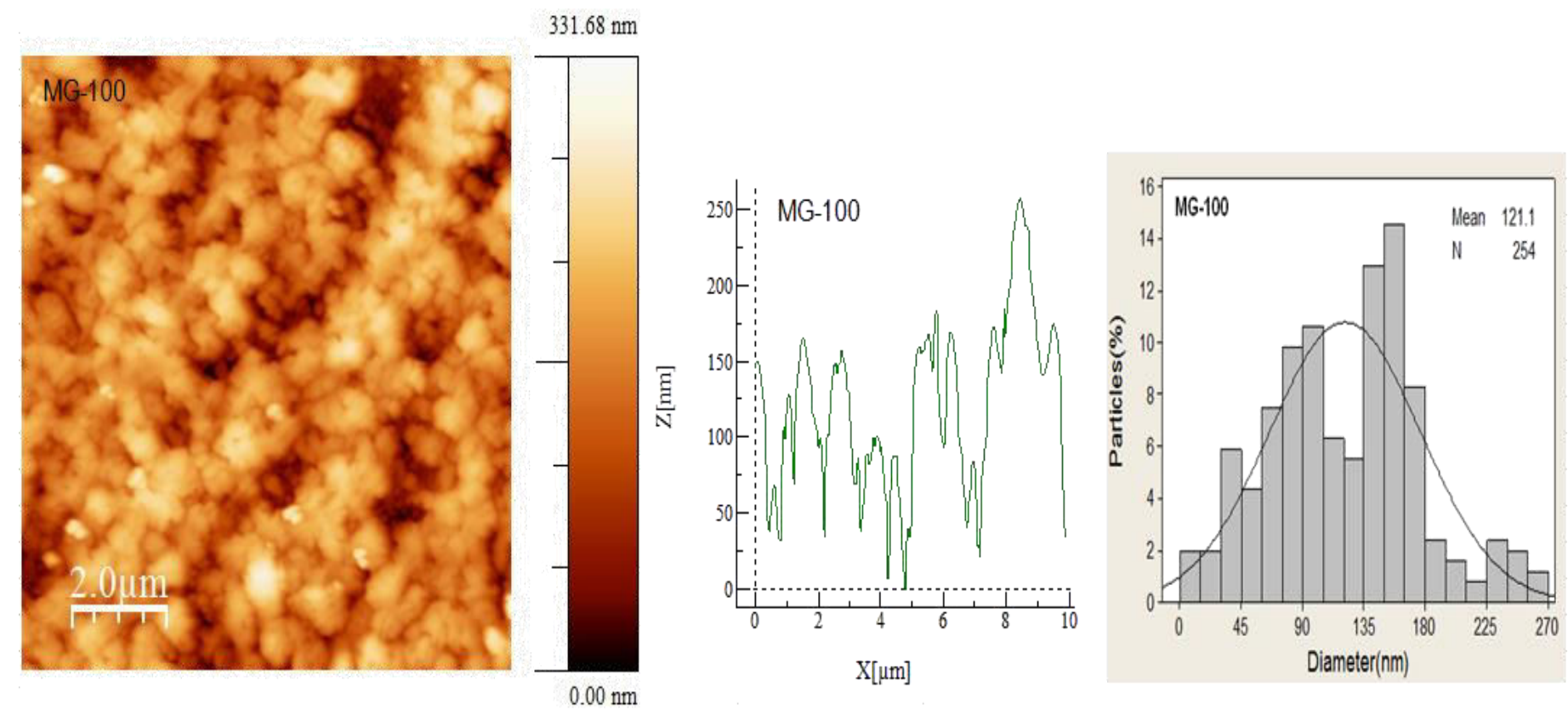

(A) 


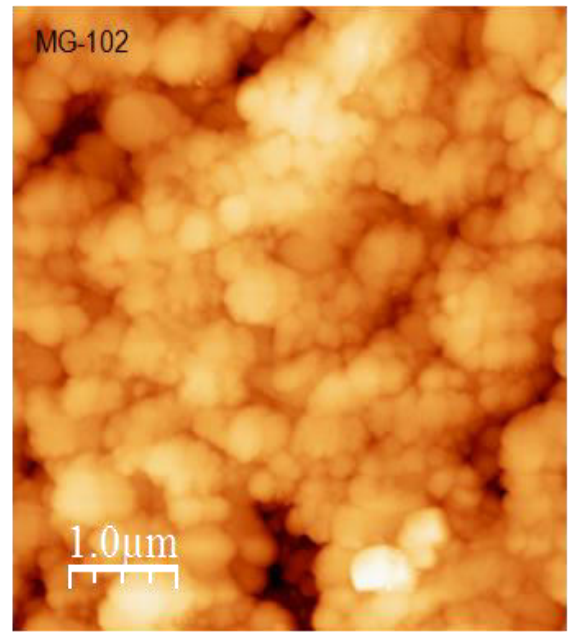

$316.24 \mathrm{~nm}$
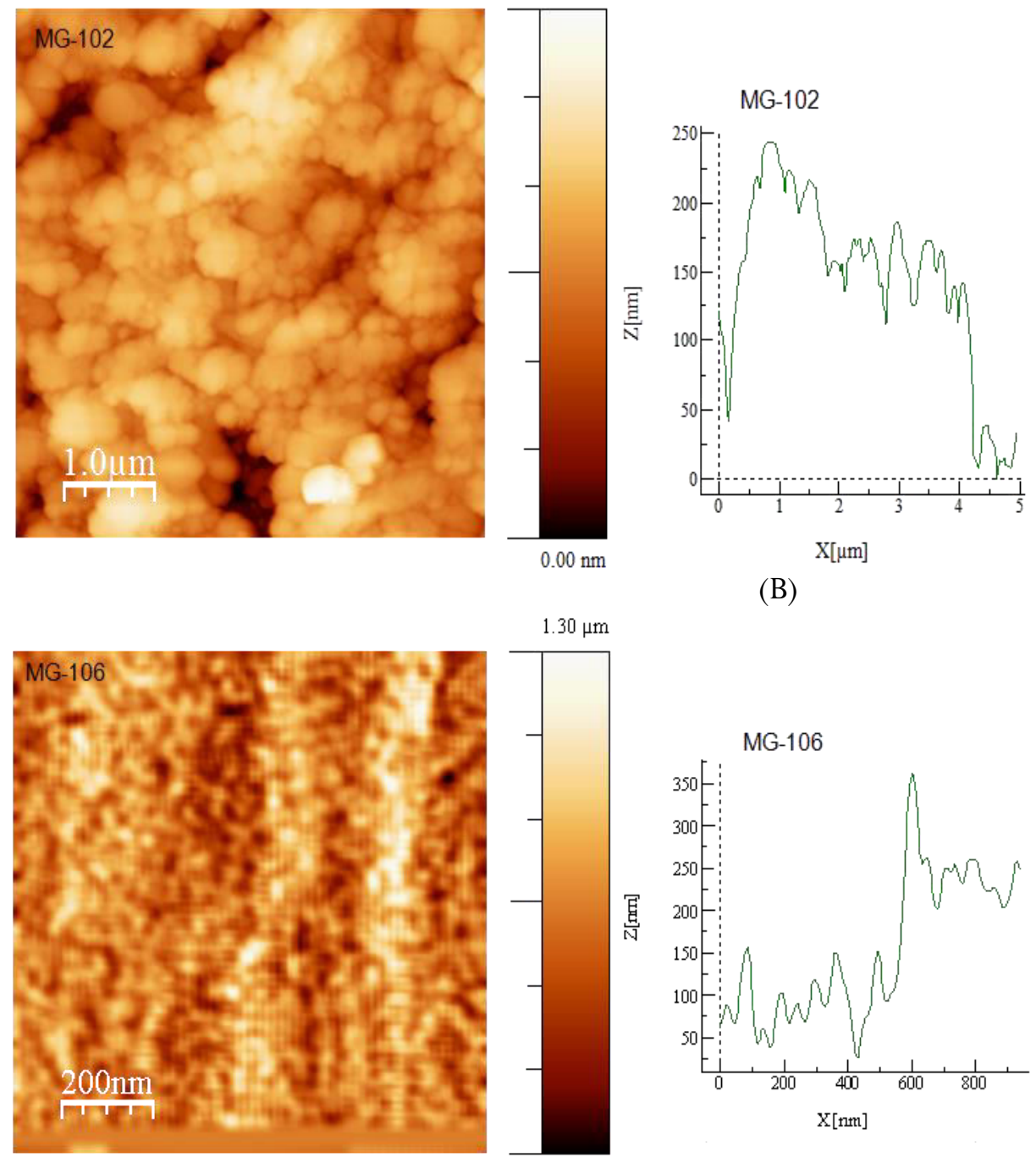

$0.00 \mu \mathrm{m}$

$139 \mu \mathrm{m}$
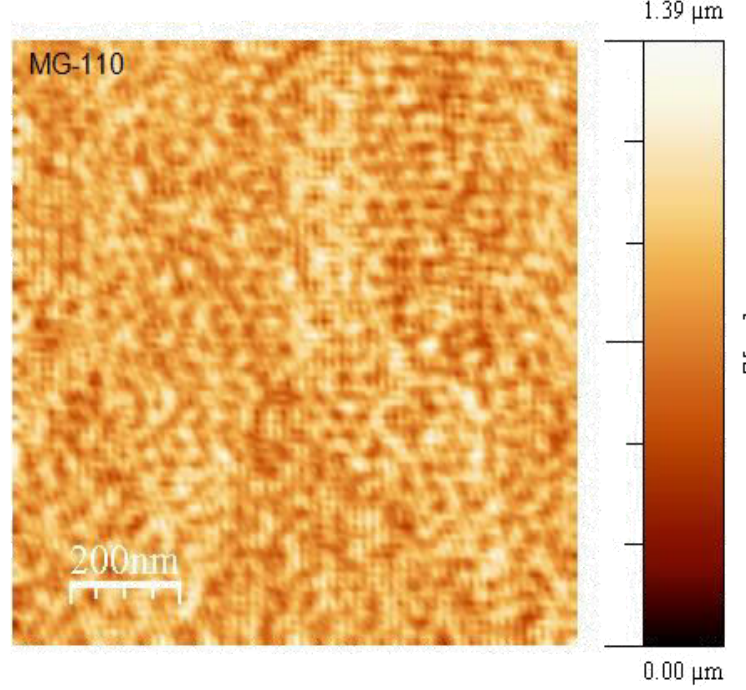

(B)
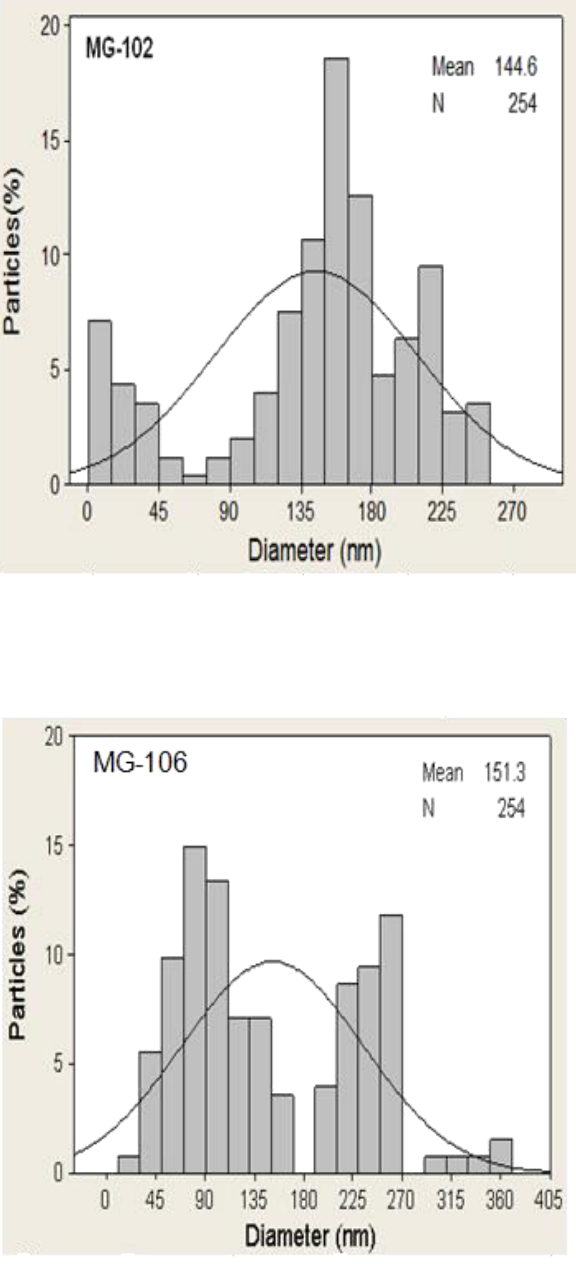

(C)
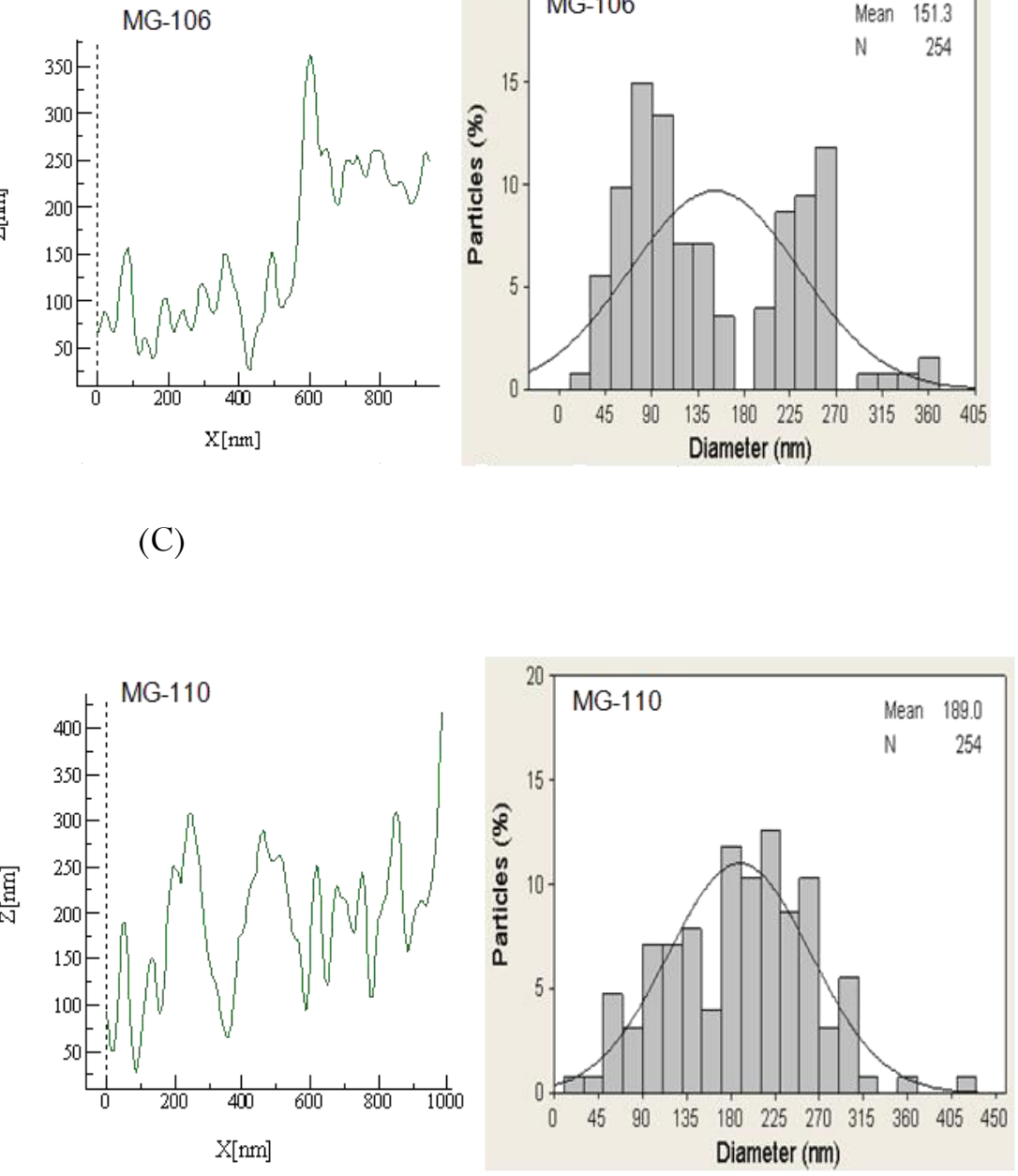

(D)

Fig. 3: AFM topography images, extracted profile and histogram of different microgels (A)MG-100, (B) MG-102, (C) MG-106, (D) MG-110 
Table 1: The comparison of microgels size measured by DLS, TEM and AFM techniques

\begin{tabular}{ccccccc}
\hline \multirow{2}{*}{ Sample Designation } & \multicolumn{2}{c}{ DLS $(\mathrm{nm})$} & \multicolumn{2}{c}{ PDI } & \multirow{2}{*}{ TEM (nm) } & \multirow{2}{*}{ AFM (nm) } \\
\cline { 2 - 5 } & $25^{\circ} \mathrm{C}$ & $50^{\circ} \mathrm{C}$ & $25^{\circ} \mathrm{C}$ & $50^{\circ} \mathrm{C}$ & & \\
\hline MG-100 & 343.6 & 132.5 & 0.436 & 0.197 & 103.0 & 121.1 \\
\hline MG-102 & 342.4 & 174.6 & 0.574 & 0.268 & 109.6 & 144.6 \\
\hline MG-106 & 487.1 & 359.9 & 0.417 & 0.296 & 123.4 & 151.3 \\
\hline MG-110 & 538.1 & 414.4 & 0.290 & 0.305 & 133.1 & 189.0 \\
\hline
\end{tabular}

\subsection{Temperature Sensitivities of Microgels}

The sensitivity of PNIPAM based microgel particles are characterized by the change in hydrodynamic diameter with respect to their temperature indicated by change in volume phase transition temperature (VPTT). The volume phase transition temperature (VPTT) of PNIPAM-MBA is about $34.5^{\circ} \mathrm{C}$ [38-39], whereas VPTT of prepared microgels was found to be $37.13^{\circ} \mathrm{C}$ to $46.5^{\circ} \mathrm{C}$ calculated from first derivative $\left(\frac{d D_{h}}{d T}\right)$ curve at each temperature [33]. At low temperature $\left(\mathrm{T}=25^{\circ} \mathrm{C}\right)$, the particles show swelling behavior thereby increased in average hydrodynamic diameter $\left(\mathrm{D}_{\mathrm{h}}\right)$ due to the hydrophilic interaction water molecules with amide groups in PNIPAM chains as shows in Table 1. However, the same microgel particles are expelled out due to the disruption of hydrogen bonding between water molecules and the hydrophilic amide groups, causing at the same time the packing up of the hydrophobic isopropyl groups in the polymer chains
Thus, it makes the particles shrink to a smaller size at higher temperature $\left(\mathrm{T}=50^{\circ} \mathrm{C}\right)$.

The size of microgels particle increases with increasing amount of Acrylamido-2-methylpropane sulphonic acid (AMPS) comonomer.

\subsection{Morphology of Microgels}

The shape and surface roughness of different microgel particles were measured from TEM and AFM images. The circularity measures the shape of particle closeness to perfect circle and values are in the range of 0 to 1 . The shape of particle is circular when the value of circularity $\cong 1$ and irregular shape when circularity value close to 0 . The calculated circularity value of microgel samples from 0.27 to 1.03 as shown in Fig.4. The lowest value observed was 0.27 for sample MG100 and has anirregular shape, $\cong 1$ for MG-102, MG106, and MG-110 and has a spherical shape. The circularity value depends on the composition and surface roughness of particles.
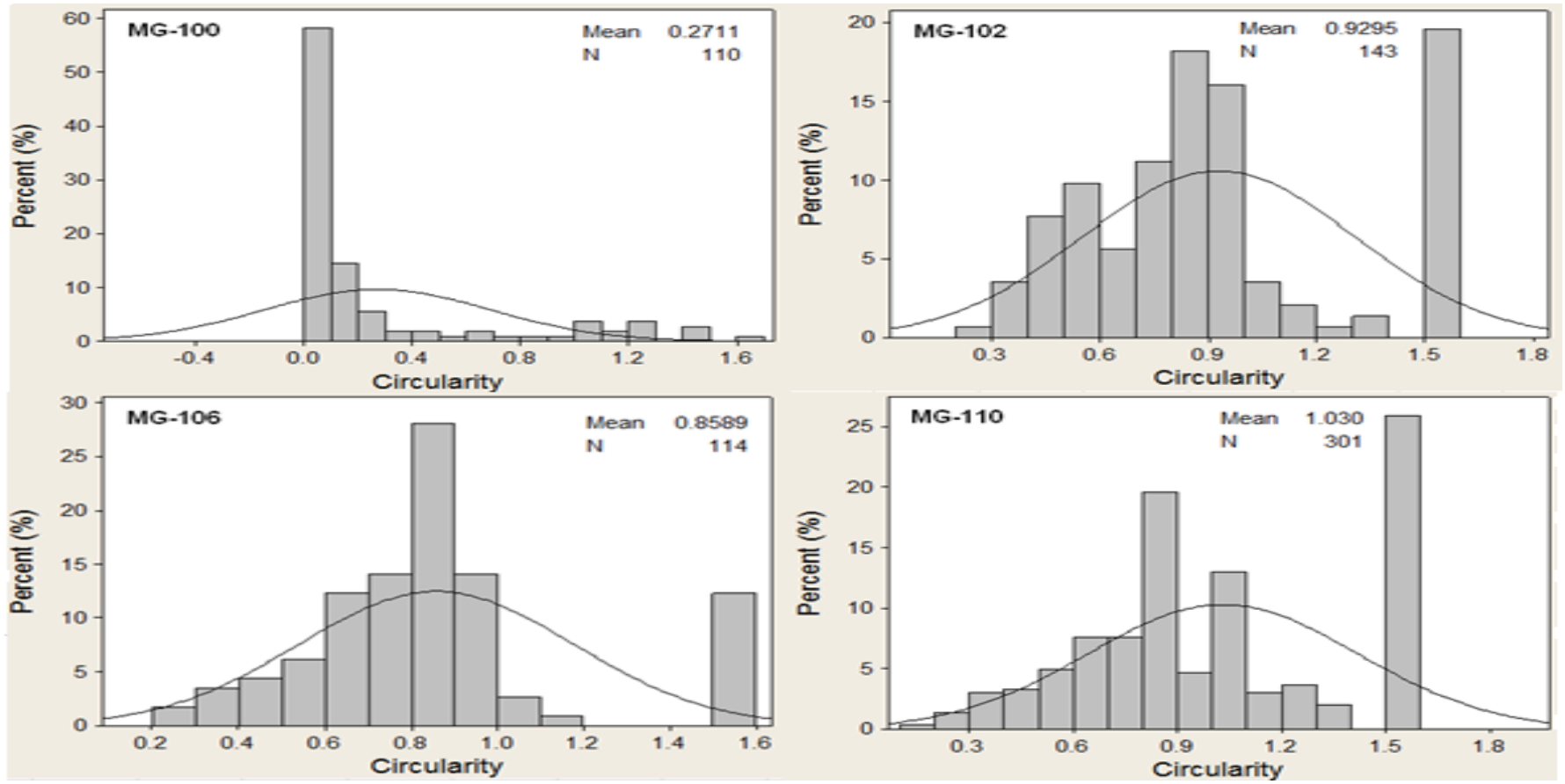

Fig. 4: The circularity calculated from different microgels MG-100, MG-102, MG-106 and MG-110 by analysis TEM images in Image J1.42q software. 
The eccentricity of a particle is a measure of how nearly circular is the particle and calculated by using equation (2). For a particle in circle shape $\varepsilon=0$ and for elliptical shape $0<\varepsilon<1$. The calculated value of circularity and eccentricity are given in the Table 2. By combination of TEM diameter with an AFM height of different microgel particles gives the sphericity and homogeneity of particles. From the calculated data, it has been observed that microgel particles seem to have heterogeneous shape and size with elliptical shape. The aggregation of particles observed due to drying induced aggregation during AFM sample preparation as the particles are sensitive to temperature.

To visualize the difference in roughness of microgel particles, AFM 3D images of scan areas of size $5 \times 5 \mu^{2}$ and $10 \times 10 \mu \mathrm{m}^{2}$ are shown in Fig. 5. The data for roughness parameters, $\mathrm{R}_{\mathrm{a}}$ and $\mathrm{R}_{\mathrm{rms}}$ for different microgel particles are presented in Table 2. It was observed that the RMS roughness value increased with the increasing AMPS concentration on microgel samples. The formation of surface roughness is due to the inhomogeneity in the network structure of particles. During the polymerization reaction, cross-linker reacts faster than NIPAM and AMPS. As a result, an inhomogeneous cross-linking density in the microgel particles is produced. Thus, the surface properties of microgels such as particle size, surface roughness strongly depend on the amount of AMPS concentration present in samples.
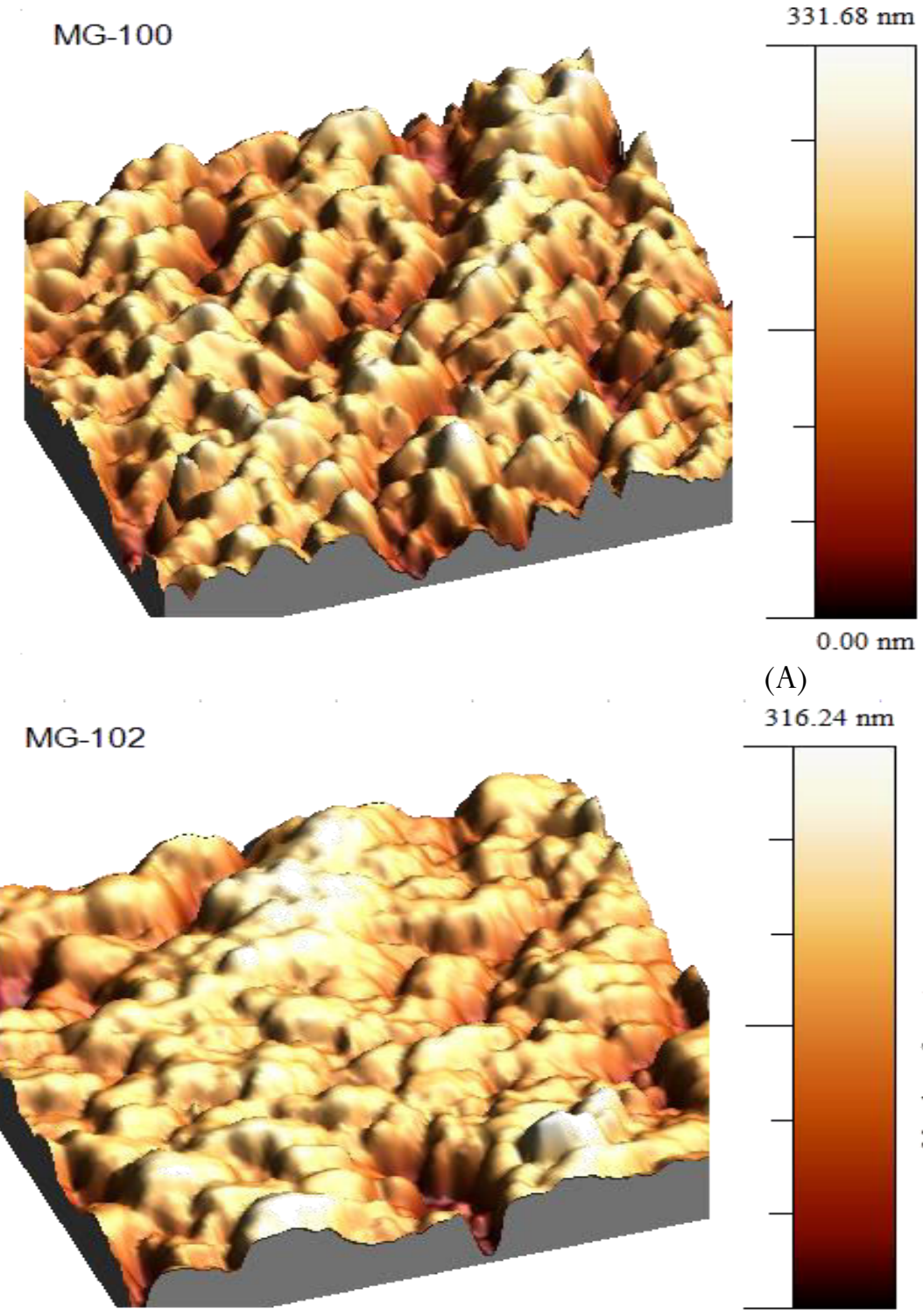

$0.00 \mathrm{~nm}$

(A)

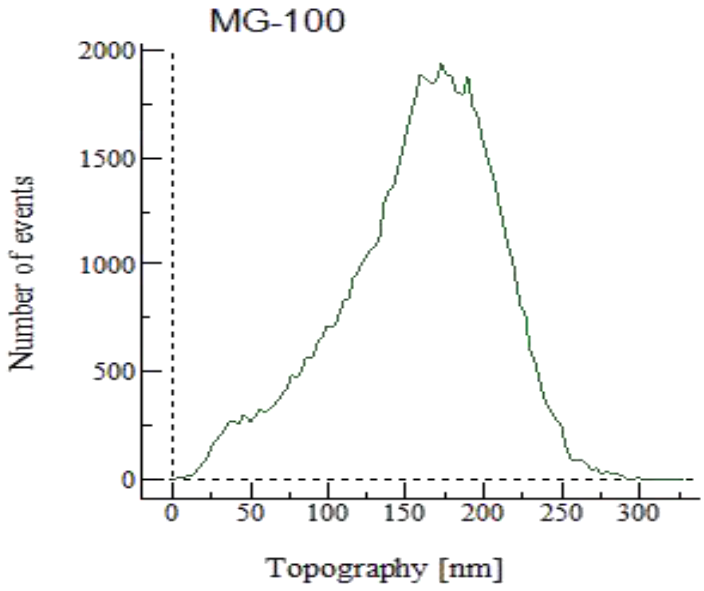

$316.24 \mathrm{~nm}$

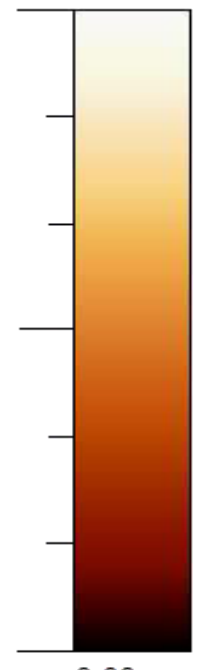

B)

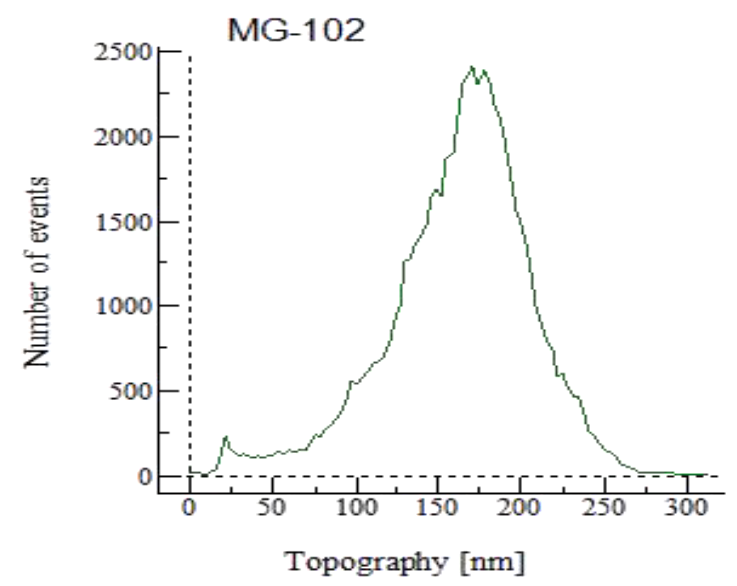



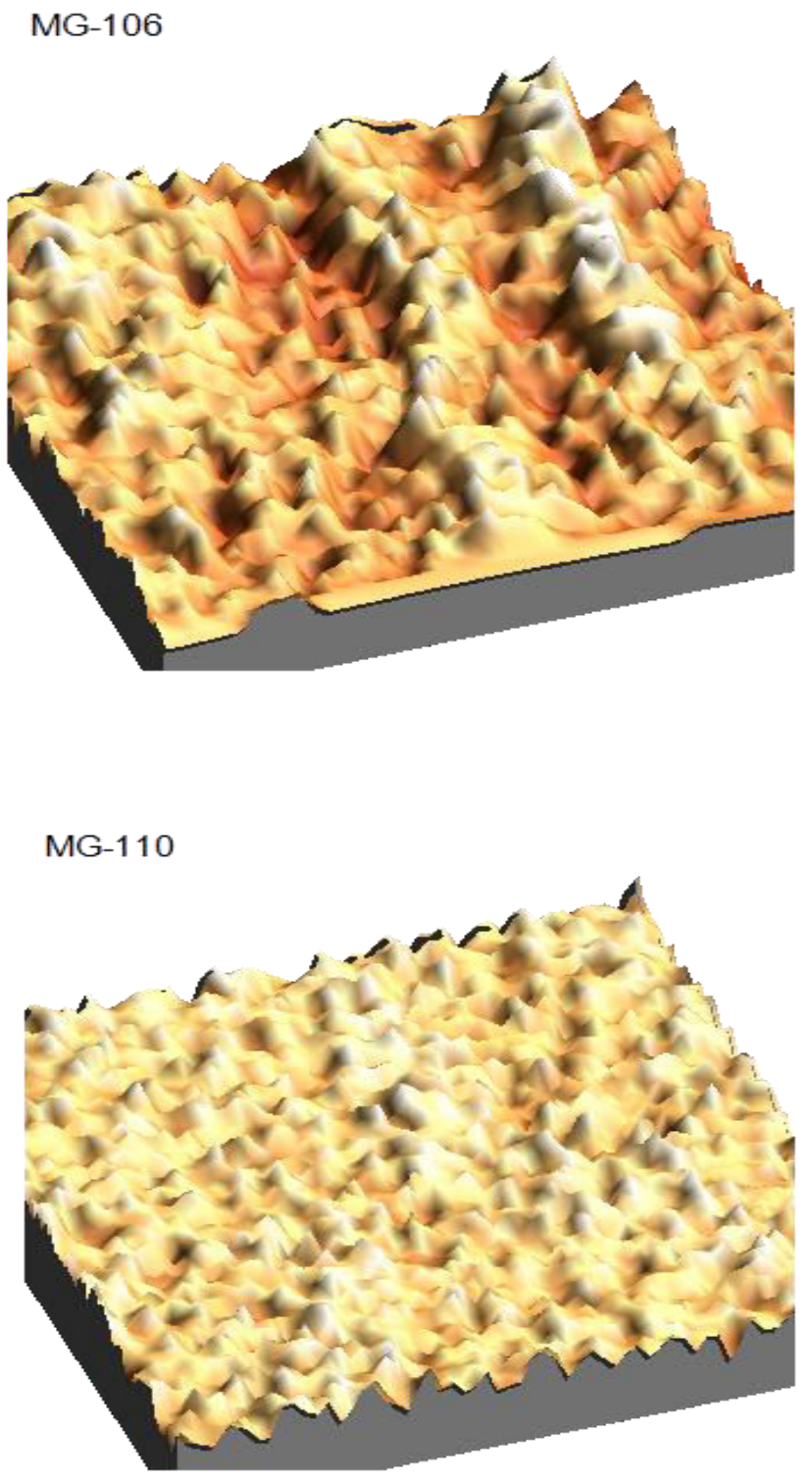

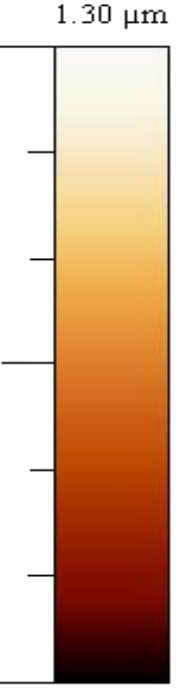

$0.00 \mu \mathrm{m}$

(C)

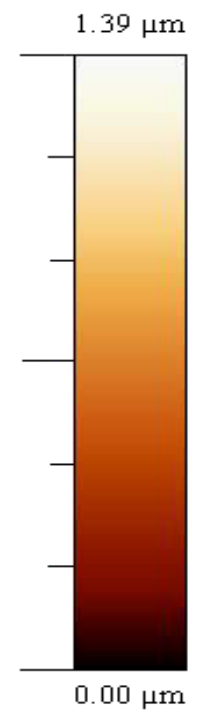

(D)

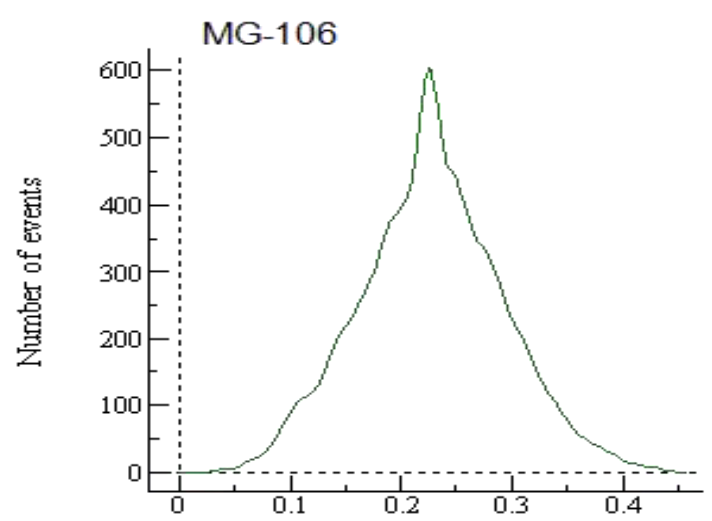

Topography $[\mu \mathrm{m}]$

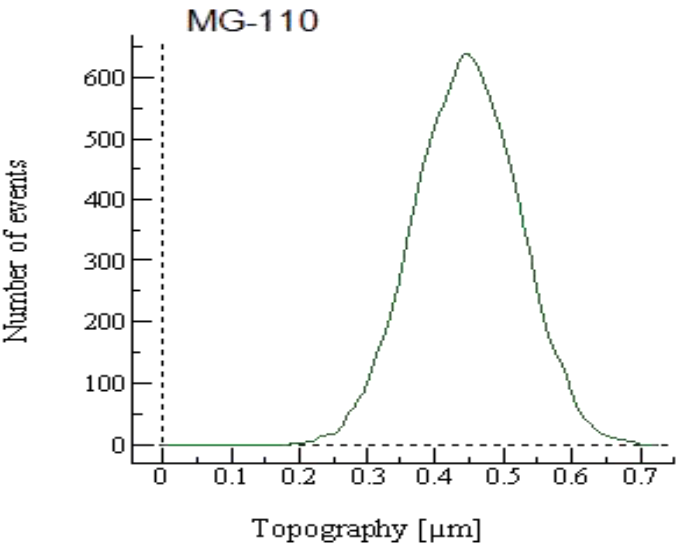

Fig. 5: AFM 3D images and extractedprofile of different microgels (A) MG-100, (B) MG-102, (C) MG106, (D) MG-110

Table 2: The data of particles shape and surface roughness measurement

\begin{tabular}{ccccc}
\hline \multirow{2}{*}{ Sample Designation } & Circularity & Eccentricity & $\begin{array}{c}\text { Soughness } \\
\text { Average }\left(\mathrm{R}_{\mathrm{a}}\right), \mathrm{nm}\end{array}$ & $\begin{array}{c}\text { Root Mean Square } \\
\text { Roughness }\left(\mathrm{R}_{\mathrm{rms}}\right), \mathrm{nm}\end{array}$ \\
\hline MG-100 & 0.2711 & 0.82 & 37.77 & 47.39 \\
\hline MG-102 & 0.9295 & 0.68 & 30.22 & 39.84 \\
\hline MG-102 & 0.9295 & 0.68 & 30.22 & 39.84 \\
\hline MG-110 & 1.03 & 0.77 & 60.3 & 75.23 \\
\hline
\end{tabular}

\section{CONCLUSION}

DLS, TEM and AFM are the powerful tool for independently analyzing the structural characteristics of microgels particles. We assessed the influence of the AMPS monomer concentration on particle size, distribution and shape were measured by DLS, TEM 
and AFM. The particle size of microgels was found to be larger size in DLS measurements and comparable size between TEM and AFM measurements. The TEM and AFM data shows that microgels have heterogeneity in shape and size. The surface roughness parameters of the microgels strongly depend on the AMPS content in microgels. An arrow size distribution of the particles leads to relatively smooth while a large polydispersed leads to more rough and textured surface. The sensitivity of microgels was decreased with increasing AMPS amount.

\section{ACKNOWLEDGEMENT}

The authors would like to thank Sophisticated Analytical Instrumentation Facility (SAIF) Department of Anatomy, All India Institute of Medical Sciences New Delhi -110029 for providing facility to perform TEM analysis and USBAS, GG S Indraprastha University, Dwarka, Delhi-110075, for providing facility to perform DLS, AFM analysis

\section{Declaration of Interest}

The authors declare no conflict of interest.

\section{REFERENCES}

1. Woodward NC, Chowdhry BZ, Snowden MJ, Leharne SA, Griffiths PC, Winnington AL. Langmuir, 2003; 19(8):3202-3211.

2. Pelton RH. Adv. Colloid Inter. Sci., 2000; 85(1):1-33.

3. Zhang X, Guo X, Yang S, Tan S, Li X, Dai H, et al. J. Appl. Polym. Sci. 2009; 112(5):3063-3070.

4. Singh TRR, McCarron PA, Woolfson AD, Donnely RF. Eur. Polym. J., 2009; 45(4):1239-1249.

5. Yoshida R, Uchida K, Kaneko Y, Sakai K, Kikuchi A, et al. Nature, 1995; 374(6519):240-242.

6. Vihola H, Laukkanen A, Hirvonen J, Tenhu H. Eur. J. Pharm. Sci., 2002; 16(1-2):69-74.

7. Carter S, Rimmer S, Rutkaile R, Swanson L, Fairclough JPA, et al. Biomacromolecules, 2006; 7(4):1124-1130.

8. Saikia A K, Aggarwal S, Mandal UK. Inter. J. Polym. Mater., 2013; 62(1):39-44.

9. Kujawa P, Ascyev V, Tenhu H, Winnik FM. Macromolecules, 2006; 39(22):7686-7693.

10. Durme KV, Rahier H, Mele BV. Macromolecules, 2005; 38(24):10155-10163.

11. Yusa SI, Fukuda K, Yamamoto T, Iwasaki Y, Watanabe A, et al. Langmuir, 2007; 23(26):12842-12848.

12. Sayil C, Okay O. J. Appl. Polym. Sci., 2002; 83(6):12281232.

13. Zohuriaan-Mehr MJ, Kabiri K, Kheirabadi M. J. Appl. Polym. Sci., 2010; 117(2):1127-1136.
14. Turan E, Demirci S, Caykara T. J. Appl. Polym. Sci. Part B:Polym. Phy., 2008; 46(16):1713-1724.

15. Lin HH, Cheng YL. Macromolecules, 2001; 34(11):37103715.

16. Plunkett KN, Kraft ML, Yu Q, Moore JS. Macromolecules, 2003; 36(11):3960-3966.

17. Kasinski A, Zielinska-Pisklak M, Oledzka E, Sobczak M. Inter. J Nanomedicine, 2020; 15(6):4541-4572.

18. Piras CC, Kay AG, Genever PG, Smith DK. J. Chem. Sci., 2021,12(11):3958-3965

19. Kulkarni AS, Tapase SR, Kodam KM, Shinde VS. Colloids \& Surfaces B:Biointerfaces, 2021; 205(9):111834.

20. Kawaguchi H. J Gel, 2020; 6(1):1-26.

21. Karg M, Pich A, Hellweg T, Hoare T, Lyon L A, et al. Langmuir, 2019; 35(19):6231-6255.

22. Hirokawa T, Tanaka T. J. Chem. Phys, 1984; 81(4):63796388.

23. Kawasaki H, Sasaki S, Maeda H. Langmuir, 1998; 14(4):773-776.

24. Wu C. Polymer, 1998; 39(19):4609-4619.

25. Kratz K, Hellweg T, Eimer W. Colloids \& Surf A; 2000; 170(2-3):137-149.

26. Senff H, Richtering W. Colloid Polym. Sci.; 2000; 278(2):830-840.

27. Debord JD, Lyon LA. J. Phys. Chem. B, 2000; 104(27):6327-6331.

28. Pelton H, Pelton HM, Morphesis A, Rowell RL. Langmuir, 1989; 5(3):816-818.

29. Ballauff M. Macromol. Chem. \& Phys. 2003; 204(2):220234.

30. Kratz K, Hellweg T, Eimer W. Polymer, 2001; 42(5):6631-6639.

31. Kollensperger G, Friedbacher G, Krammer A, Grasserbauer M. J. Anal. Chemistry; 1999; 363(4):323332.

32. Montasser I, Fessi H, Coleman AW. Eur. J. Pharm. Biopharm. 2002; 54(3):281-296.

33. Saikia AK, Mandal UK, Aggarwal S. J Polym Res; 2013; 20(1):31-37.

34. Horcas I, Fernandez R, Gomez-Rodriguez JM, Colchero J, Gomez-Herrero J, Baro AM. Rev. Sci. Instrum., 2007; 78(1):013705.

35. Stevenson APZ, Bea DB, Civit S, Contera SA, Cerveto AI, Trigueros S. Nanoscale Research Letters, 2012; 7(1):151-158.

36. Wang Q, Zhao Y, Yang Y, Xu H, Yang X. Colloid Polym Sci; 2007; 285(5):515-521

37. Teulon JM, Godon C, Chantalat L, Moriscot C, Cambedouzou J, et al. Nanomaterials, 2019; 9(1):18-46.

38. Hirotsu S, Hirokawa Y, Tanaka T. J. Chem. Phys., 1987; 87(2):1392-1395.

39. Hertle Y, Zeiser M, Hasenöhrl C, Busch P, Hellweg T. Colloid Polym Sci., 2010; 288(10-11):1047-1059. 